\title{
Liquid Embolic Agents for Endovascular Embolization: Evaluation of an Established (Onyx) and a Novel (PHIL) Embolic Agent in an In Vitro AVM Model
}

\author{
(DD.F. Vollherbst, (D) C.M. Sommer, (D) C. Ulfert, (D). Pfaff, (D) M. Bendszus, and (i) M.A. Möhlenbruch
}

\begin{abstract}
BACKGROUND AND PURPOSE: Embolization plays a key role in the treatment of arteriovenous malformations. The aim of this study was to evaluate an established (Onyx) and a novel (precipitating hydrophobic injectable liquid [PHIL]) liquid embolic agent in an in vitro AVM model.

MATERIALS AND METHODS: An AVM model was integrated into a circuit system. The artificial nidus (subdivided into 28 honeycomb-like sections) was embolized with Onyx 18 (group Onyx; $n=8$ ) or PHIL 25 (group PHIL; $n=8$ ) with different pause times between the injections (30 and 60 seconds, $n=4$ per study group) by using a 1.3F microcatheter. Procedure times, number of injections, embolization success (defined as the number of filled sections of the artificial nidus), volume of embolic agent, and frequency and extent of reflux and draining vein embolization were assessed.

RESULTS: Embolization success was comparable between Onyx and PHIL. Shorter pause times resulted in a significantly higher embolization success for PHIL (median embolization score, 28 versus 18; $P=.011$ ). Compared with Onyx, lower volumes of PHIL were required for the same extent of embolization (median volume per section of the artificial nidus, 15.5 versus $3.6 \mu \mathrm{L} ; P<.001$ ).

CONCLUSIONS: While the embolization success was comparable for Onyx and PHIL, pause time had a considerable effect on the embolization success in an in vitro AVM model. Compared with Onyx, lower volumes of PHIL were required for the same extent of embolization.
\end{abstract}

ABBREVIATIONS: DMSO = dimethyl-sulfoxide; EVOH = ethylene-vinyl alcohol copolymer; LEA = liquid embolic agent; PHIL = precipitating hydrophobic injectable liquid

A rteriovenous malformations are complex vascular structures composed of feeding arteries, an intervening network of small pathologic blood vessels (the so-called nidus), and draining veins. The lack of an intervening capillary bed allows high-flow arteriovenous shunting of blood. While AVMs can occur throughout the entire body, cerebral AVMs are of particular relevance due to their ability to cause impairing neurologic symptoms and their considerable risk of hemorrhage. ${ }^{1}$

Alone or in combination with microneurosurgery and stereotactic radiation therapy, embolization plays an important role in

Received January 11, 2017; accepted after revision February 23.

From the Department of Neuroradiology (D.F.V., C.U., J.P., M.B., M.A.M.) and Clinic for Diagnostic and Interventional Radiology (C.M.S.), University Hospital Heidelberg, Heidelberg, Germany; and Clinic for Diagnostic and Interventional Radiology (C.M.S.), Klinikum Stuttgart, Stuttgart, Germany.

This study was technically supported by MicroVention and Medtronic. The authors had full control of the data and its analysis throughout the study.

Please address correspondence to Markus A. Möhlenbruch, MD, Department of Neuroradiology, University Hospital Heidelberg, INF 400, 69120 Heidelberg, Germany; e-mail: markus.moehlenbruch@med.uni-heidelberg.de

http://dx.doi.org/10.3174/ajnr.A5203 the management of cerebral AVMs. ${ }^{2}$ The aim of AVM embolization is complete filling of the nidus, while unwanted reflux into the feeding arteries should be minimized and premature embolization of the draining veins should be avoided. ${ }^{3}$

A wide variety of embolic agents has been and is currently used for embolization of AVMs. At present, the liquid embolic agents (LEAs) ethylene-vinyl alcohol copolymer (EVOH) and $n$-butyl cyanoacrylate are used most frequently. ${ }^{4}$ Although the embolization results have improved since the introduction of EVOH-based LEAs with rates of complete obliteration ranging from $16 \%$ to $100 \%$, the success rate of AVM embolization, especially for complex AVMs, is not yet satisfying. ${ }^{2,3}$ Currently, new LEAs are being introduced to improve embolization features, such as embolization efficacy, intraprocedural handling, and control. Furthermore, their use should improve fluoroscopic visibility and reduce artifacts in postinterventional imaging.

The aim of this study was to evaluate an established EVOHbased embolic agent and a novel copolymer-based embolic agent in an in vitro AVM model. 


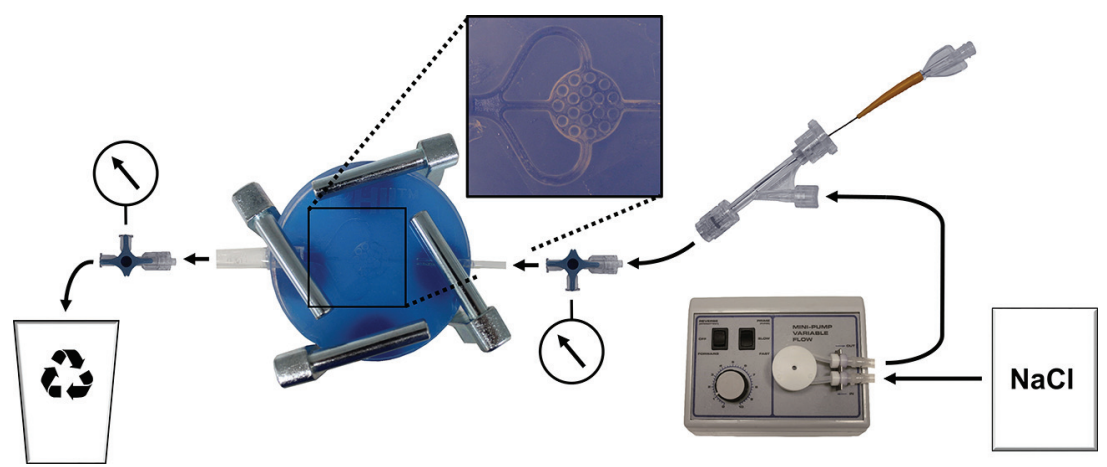

FIG 1. Illustration of the experimental setup. Note that sodium chloride solution $(\mathrm{NaCl})$ was pumped into the circuit system with a constant-flow pump (arrows indicating the direction of flow). A microcatheter was inserted via a hemostatic Y-adapter. Using 3-way stopcocks, we measured intraluminal pressures (manometer symbols).

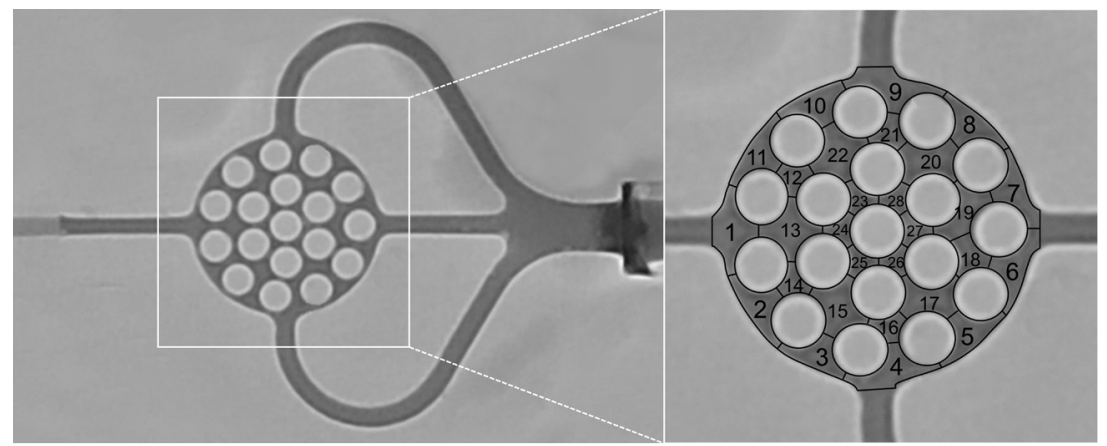

FIG 2. Definition of the embolization success. Note that after we filled the nonembolized AVM model with pure contrast agent, the artificial nidus was subdivided into 28 honeycomb-like sections.

\section{MATERIALS AND METHODS \\ Embolic Agents}

Onyx (Covidien, Irvine, California) is composed of nonadhesive EVOH dissolved in dimethyl-sulfoxide (DMSO) in a mixture with tantalum powder, the latter causing radiopacity. To ensure proper mixing of the tantalum powder, we keep Onyx vials on a shaker (Vortex Genie 2; Scientific Industries, Bohemia, New York) for at least 20 minutes before injection. Three concentrations of Onyx are available: Onyx 18, 20, and 34 (increasing in viscosity; numbers indicating viscosity in centipoise).

Precipitating hydrophobic injectable liquid (PHIL; MicroVention, Tustin, California) is composed of a nonadhesive copolymer (polylactide-co-glycolide and polyhydroxyethylmethacrylate) dissolved in DMSO with an iodine component (triiodophenol) covalently bound to the copolymer, causing radiopacity. PHIL is ready to use in prefilled syringes of $1 \mathrm{~mL}$ and does not require shaking before injection. Three concentrations of PHIL are available: PHIL 25, 30, and 35 (increasing in viscosity, numbers indicating concentration in weight/weight).

\section{AVM Model}

The in vitro AVM model and the experimental setting are illustrated in Fig 1. The AVM model, made of silicone, consisted of an afferent tube, representing the feeding artery, supplying the artificial nidus; a round, flat, honeycomb-like 3D space; and 3 efferent tubes, representing 3 draining veins. It was placed between 2 congruent glass plates, attached with 4 screw clamps, ensuring complete tightness of the model. The diameter of the feeding artery and the draining veins was $2 \mathrm{~mm}$; the artificial nidus measured $15 \times 15 \times 3 \mathrm{~mm}$ with a volume of $311 \mathrm{~mm}^{3}$. The artificial nidus was subdivided into 28 honeycomb-like sections (Fig 2). The AVM model was integrated into a circuit system with a constant flow of sterile $0.9 \%$ (weight/ volume) sodium chloride solution with a temperature between $20^{\circ} \mathrm{C}$ and $25^{\circ} \mathrm{C}$ and a volume flow of $120 \mathrm{~mL} /$ minute. Using 3-way stopcocks, we measured endoluminal pressures proximal und distal to the nonembolized artificial nidus 10 times. Proximal to the AVM model, a hemostatic Y-adapter was installed for access.

\section{Embolization Technique}

A DMSO-compatible 1.3F microcatheter (Headway Duo; MicroVention) was inserted into the circuit system via the Y-adapter. The catheter tip was positioned $3 \mathrm{~mm}$ proximal to the artificial nidus. After flushing the catheter with 1 $\mathrm{mL}$ of DMSO, we performed manual embolization with 1-mL DMSO-compatible syringes. Embolization was performed under fluoroscopic guidance (Artis Q biplane system; Siemens, Erlangen, Germany) until reflux, draining vein embolization, or complete embolization of the artificial nidus occurred. In case of reflux or draining vein embolization, embolization was stopped and paused for 30 or 60 seconds (see "Study Groups"). Reflux of 10 $\mathrm{mm}$ into the feeding artery and embolization of the proximal $15 \mathrm{~mm}$ of the draining veins were tolerated. In case of reflux of $>10 \mathrm{~mm}$ or draining vein embolization of $>15 \mathrm{~mm}$, the embolization procedure was terminated.

\section{Study Groups}

In total, 16 embolization procedures were performed. For 8 procedures, Onyx 18 (group Onyx) and for 8 procedures PHIL 25 (group PHIL) were used as the LEA. Pause time between the injections was set to 30 or 60 seconds ( $n=4$ per study group). Accordingly, we defined 4 subgroups: group Onyx_30s $(n=4)$, group Onyx_60s $(n=4)$, group PHIL_30s $(n=4)$, and group PHIL_60s $(n=4)$.

\section{Study Goals}

The intention of each embolization procedure was complete filling of the artificial nidus. According to the 28 honeycomb-like sections of the artificial nidus (Fig 2), we graded embolization success from $0 / 28$ sections (no embolization of the artificial nidus) to $28 / 28$ sections (complete embolization of the artificial nidus). The number of filled sections of the artificial nidus at the time of the first reflux or draining vein embolization (first pause) 


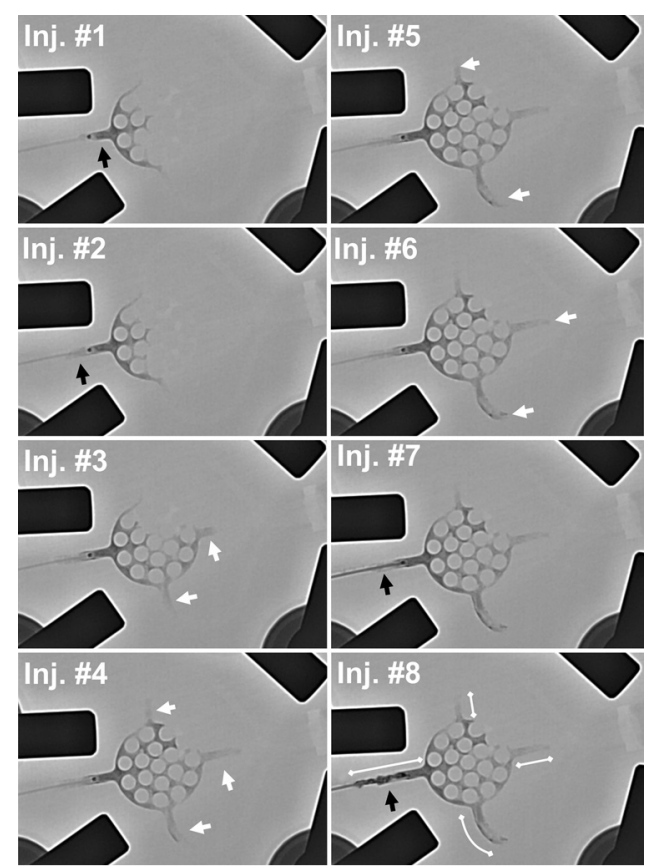

FIG 3. Exemplary embolization procedure. Note the exemplary embolization procedure shown for group Onyx_60s. Eight injections were performed. For 4 injections, embolization of draining veins (white arrows) and, for 4 injections, reflux (black arrows) were the reasons for injection stop. After the eighth injection, the reflux distance exceeded $1.5 \mathrm{~cm}$ and the procedure was terminated. After termination, reflux distance and distance of the embolized draining veins were measured (white double arrows injection [Inj.] No. 8) and the filled sections of the artificial nidus were assessed (according to Fig 2).

was determined. Total procedural time, injection time (defined as the duration of all injections per procedure without pause time), time per injection (defined as the time of a single injection until reflux, draining vein embolization, or complete filling of the artificial nidus), and number of injections per procedure were documented. The volume of the LEA per procedure (less the dead space of the microcatheter of $0.35 \mathrm{~mL}$ ) was assessed, and the volume of the LEA, required for filling 1 section of the artificial nidus, was calculated (less the dead space of the microcatheter and the volume of LEA in the feeding artery and the draining veins). The respective number of reflux events and draining vein embolization events was documented. For each embolization procedure, the extent of reflux and of draining vein embolization was assessed by measuring the embolized distance of the respective structure (Fig 3).

\section{Statistics}

GraphPad Prism software (Version 6.00; GraphPad Software, San Diego, California) was used for data analysis. Quantitative data are presented as medians (range [minimum value; maximum value]). To evaluate statistical differences between group Onyx and group PHIL, we performed the Mann-Whitney $U$ test. To evaluate statistical differences among the subgroups, we performed the Kruskal-Wallis test with a post hoc Dunn test. A $P$ value of $<.05$ was significant.

\section{RESULTS}

All embolization procedures could be performed as planned. No technical failure, such as catheter occlusion or catheter entrap-

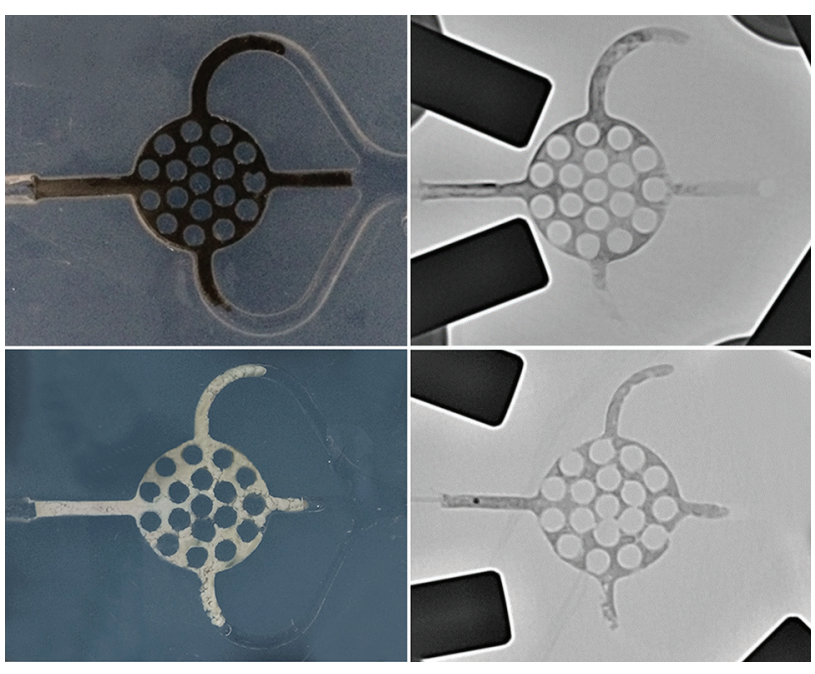

FIG 4. Photographs of Onyx and PHIL after embolization with fluoroscopic correlation. Upper rows, Example from group Onyx_30s. Note the black appearance of the Onyx cast. Lower rows, Example from group PHIL_30s. Note the white appearance of the PHIL cast.

ment, was observed. Endoluminal pressure proximal to the artificial nidus was $70 \mathrm{~mm} \mathrm{Hg}(70 \mathrm{~mm} \mathrm{Hg}, 70 \mathrm{~mm} \mathrm{Hg}$ ), and distal to the artificial nidus, it was $13 \mathrm{~mm} \mathrm{Hg}(13 \mathrm{~mm} \mathrm{Hg}, 13 \mathrm{~mm} \mathrm{Hg}$ ), resulting in a median pressure gradient of $57 \mathrm{~mm} \mathrm{Hg}$. Both embolic agents were sufficiently visible under fluoroscopy.

A representative embolization procedure is shown in Fig 3. Representative photographs after embolization with fluoroscopic correlation are shown in Fig 4. Results are presented in Tables 1 and 2 and illustrated in Fig 5.

When we compared group Onyx and group PHIL, the median amount of LEA per embolization procedure was significantly higher for group Onyx $(0.48 \mathrm{~mL}$ versus $0.15 \mathrm{~mL}, P=.002)$. This finding was even more distinct for the median amount of LEA per filled section of the artificial nidus ( 15.5 versus $3.6 \mu \mathrm{L}, P<.001$ ). The median number of filled sections of the artificial nidus at the time of the first reflux or draining vein embolization was significantly higher for group Onyx (13 versus $9, P=.032$ ). However, the median number of filled sections of the artificial nidus (embolization success) did not show significant differences between group Onyx and group PHIL (24 versus 20, $P=.780$ ). Also, total procedural time, injection time, time per injection, number of injections, and the frequency and the extent of reflux and draining vein embolization did not differ.

When we compared group Onyx_30s and group Onyx_60s, subgroup analysis revealed a trend toward a higher median number of filled sections of the artificial nidus for group Onyx_60s, however, without reaching statistical significance (27 versus 21 , $P=.169)$. The median injection time was considerably higher for group Onyx_30s (34 versus 14 seconds, $P=.270$ ), also without a statistically significant difference.

When we compared group PHIL_30s and group PHIL_60s, subgroup analysis revealed a significantly higher median number of filled sections of the artificial nidus for group PHIL_30s (28 versus $18, P=.011)$.

AJNR Am J Neuroradiol 38:1377-82 Jul 2017 www.ajnr.org 
Table 1: Procedure times, number of injections per procedure, and required volume of LEA ${ }^{a}$

\begin{tabular}{|c|c|c|c|c|c|}
\hline & \multicolumn{2}{|c|}{ Onyx } & \multicolumn{2}{|c|}{ PHIL } & \multirow{2}{*}{$\begin{array}{l}P \text { Value }_{\text {Onyx vs PHIL' }}, \mathrm{b} \\
P \text { Value }_{\text {subgroups }}\end{array}$} \\
\hline & Onyx_30s & Onyx_60s & PHIL_30s & PHIL_60s & \\
\hline \multirow{2}{*}{ Total procedure time (sec) } & \multicolumn{2}{|c|}{$645(271-845)$} & \multicolumn{2}{|c|}{$561(375-960)$} & .959 \\
\hline & $\begin{array}{l}572 \\
(271-685)\end{array}$ & $\begin{array}{c}645 \\
(565-845)\end{array}$ & $\begin{array}{c}483 \\
(375-575)\end{array}$ & $\begin{array}{c}742 \\
(496-960)\end{array}$ & .125 \\
\hline \multirow[t]{2}{*}{ Injection time (sec) } & \multicolumn{2}{|c|}{$250(91-285)$} & \multicolumn{2}{|c|}{$152(88-305)$} & .235 \\
\hline & $\begin{array}{l}155 \\
(91-250)\end{array}$ & $\begin{array}{l}263 \\
(250-285)\end{array}$ & $\begin{array}{c}193 \\
(88-305)\end{array}$ & $\begin{array}{c}142 \\
(126-180)\end{array}$ & .093 \\
\hline \multirow[t]{2}{*}{ Time per injection (sec) } & \multicolumn{2}{|c|}{$23(7-44)$} & \multicolumn{2}{|c|}{$14(9-33)$} & .279 \\
\hline & $\begin{array}{c}14 \\
(7-17)\end{array}$ & $\begin{array}{c}34 \\
(29-44)\end{array}$ & $\begin{array}{c}21 \\
(9-33)\end{array}$ & $\begin{array}{c}11 \\
(11-18)\end{array}$ & .067 \\
\hline \multirow[t]{2}{*}{ Injections per procedure (No.) } & \multicolumn{2}{|c|}{$9(6-19)$} & \multicolumn{2}{|c|}{$10(7-14)$} & .749 \\
\hline & $\begin{array}{c}13 \\
(7-19)\end{array}$ & $\begin{array}{c}8 \\
(6-19)\end{array}$ & $\begin{array}{l}10 \\
(7-14)\end{array}$ & $\begin{array}{c}11 \\
(7-14)\end{array}$ & .240 \\
\hline \multirow[t]{2}{*}{ Volume of LEA per procedure $(\mathrm{mL})$} & \multicolumn{2}{|c|}{$0.48(0.25-0.65)$} & \multicolumn{2}{|c|}{$0.15(0.10-0.35)$} & .002 \\
\hline & $\begin{array}{c}0.53 \\
(0.25-0.65)\end{array}$ & $\begin{array}{c}0.45 \\
(0.35-0.50)\end{array}$ & $\begin{array}{c}0.23 \\
(0.15-0.35)\end{array}$ & $\begin{array}{c}0.13 \\
(0.10-0.20)\end{array}$ & $\begin{array}{c}.013 \\
\text { (Onyx_30s vs PHIL_60s) }\end{array}$ \\
\hline \multirow{2}{*}{$\begin{array}{l}\text { Volume of LEA per honeycomb-like section } \\
\text { of the artificial nidus }(\mu \mathrm{L})\end{array}$} & \multicolumn{2}{|c|}{$15.5(10.1-27.4)$} & \multicolumn{2}{|c|}{$3.6(0.6-9.5)$} & $-<.001$ \\
\hline & $\begin{array}{c}19.5 \\
(14.3-27.4)\end{array}$ & $\begin{array}{c}13.3 \\
(10.1-17.5)\end{array}$ & $\begin{array}{c}5.2 \\
(2.6-9.5)\end{array}$ & $\begin{array}{c}2.9 \\
(0.6-6.5)\end{array}$ & $\begin{array}{c}.006 \\
\text { (Onyx_30s vs PHIL_60s) }\end{array}$ \\
\hline
\end{tabular}

Note:-Onyx indicates Onyx 18; PHIL, PHIL 25.

a Data presented as median (range).

${ }^{\mathrm{b}}$ Mann-Whitney $U$ test.

' Kruskal-Wallis test with the post hoc Dunn test.

Table 2: Number of injection stops due to reflux or draining vein embolization, extent of reflux and draining vein embolization, and filled honeycomb-like sections of the artificial nidus ${ }^{\mathrm{a}}$

\begin{tabular}{|c|c|c|c|c|c|}
\hline & \multicolumn{2}{|c|}{ Onyx } & \multicolumn{2}{|c|}{ PHIL } & \multirow{2}{*}{$\begin{array}{l}P \text { Value }_{\text {Onyx vs PHIL,', }} \\
P \text { Value }_{\text {subgroups }}\end{array}$} \\
\hline & Onyx_30s & Onyx_60s & PHIL_30s & PHIL_60s & \\
\hline \multirow[t]{2}{*}{ Injection stops due to reflux (No.) } & \multicolumn{2}{|c|}{$5(1-10)$} & \multicolumn{2}{|c|}{$6(2-11)$} & .633 \\
\hline & $\begin{array}{c}7 \\
(4-10)\end{array}$ & $\begin{array}{c}3 \\
(1-5)\end{array}$ & $\begin{array}{c}6 \\
(2-7)\end{array}$ & $\begin{array}{c}5 \\
(3-11)\end{array}$ & .251 \\
\hline \multirow[t]{2}{*}{ Injection stops due to embolization of draining veins (No.) } & \multicolumn{2}{|c|}{$6(3-10)$} & \multicolumn{2}{|c|}{$5(3-8)$} & .956 \\
\hline & $\begin{array}{c}7 \\
(3-10)\end{array}$ & $\begin{array}{c}5 \\
(4-6)\end{array}$ & $\begin{array}{c}5 \\
(3-8)\end{array}$ & $\begin{array}{c}6 \\
(3-8)\end{array}$ & .778 \\
\hline \multirow[t]{2}{*}{ Reflux distance (mm) } & \multicolumn{2}{|c|}{$10.3(5.2-11.4)$} & \multicolumn{2}{|c|}{$10.9(7.7-13.0)$} & .156 \\
\hline & $\begin{array}{c}10.3 \\
(5.2-10.7)\end{array}$ & $\begin{array}{c}9.7 \\
(7.2-11.4)\end{array}$ & $\begin{array}{c}9.6 \\
(7.7-13.0)\end{array}$ & $\begin{array}{c}11.5 \\
(10.9-13.0)\end{array}$ & .164 \\
\hline \multirow[t]{2}{*}{ Draining vein distance (mm) } & \multicolumn{2}{|c|}{$17.2(5.1-20.6)$} & \multicolumn{2}{|c|}{$15.0(12.9-22.6)$} & .683 \\
\hline & $\begin{array}{c}17.2 \\
(5.1-20.6)\end{array}$ & $\begin{array}{c}17.5 \\
(14.8-20.2)\end{array}$ & $\begin{array}{c}16.3 \\
(13.3-22.6)\end{array}$ & $\begin{array}{c}13.8 \\
(12.9-17.5)\end{array}$ & .457 \\
\hline \multirow{2}{*}{$\begin{array}{l}\text { Filled honeycomb-like sections of the artificial nidus at first } \\
\text { reflux or draining vein embolization (No.) }\end{array}$} & \multicolumn{2}{|c|}{$13(8-20)$} & \multicolumn{2}{|c|}{$9(6-14)$} & .032 \\
\hline & $\begin{array}{c}12 \\
(8-20)\end{array}$ & $\begin{array}{c}13 \\
(13-15)\end{array}$ & $\stackrel{9}{9}$ & $\begin{array}{c}10 \\
(6-14)\end{array}$ & .109 \\
\hline \multirow[t]{2}{*}{ Filled honeycomb-like sections of the artificial nidus (No.) } & \multicolumn{2}{|c|}{$24(14-28)$} & \multicolumn{2}{|c|}{$20(14-28)$} & .791 \\
\hline & $\begin{array}{c}21 \\
(14-24)\end{array}$ & $\begin{array}{c}27 \\
(24-28)\end{array}$ & $\begin{array}{c}28 \\
(22-28)\end{array}$ & $\begin{array}{c}18 \\
(14-18)\end{array}$ & $\begin{array}{c}.011 \\
\text { (PHIL_30s vs. PHIL_60s) }\end{array}$ \\
\hline
\end{tabular}

Note:-Onyx indicates Onyx 18; PHIL, PHIL 25.

a Data presented as median (range).

b Mann-Whitney $U$ test.

${ }^{c}$ Kruskal-Wallis test with the post hoc Dunn test.

\section{DISCUSSION}

In this experimental study, the established LEA Onyx and the novel LEA PHIL were evaluated and compared in an in vitro AVM model. As a major finding of this study, the embolization success was comparable for Onyx and PHIL. However, pause time between injections had a considerable influence on the embolization success. For the same extent of embolization, lower volumes of PHIL compared with Onyx were required.

Since its introduction in 1990, the EVOH-based LEA Onyx has gained increasing acceptance as an effective agent for embolization of AVMs and AVFs. ${ }^{5-7}$ The major advantages of Onyx over other embolic agents, such as $n$-BCA, are its low viscosity and its delayed precipitation, offering increased embolization control and efficacy. ${ }^{8}$ Despite its high embolization potential and the advantages of Onyx over other LEAs, there are still several shortcomings reported by neurointerventionalists, such as long procedure times caused by the relatively long precipitation process of Onyx, impaired visibility during longer embolization procedures, impaired visibility of the microcatheter tip during embolization, artifacts in control imaging and in imaging for irradiation planning, hazards during surgical resection (sparking and combustion), and its preinterventional preparation process. ${ }^{9}$

PHIL is a novel LEA, introduced in 2015 by MicroVention, 

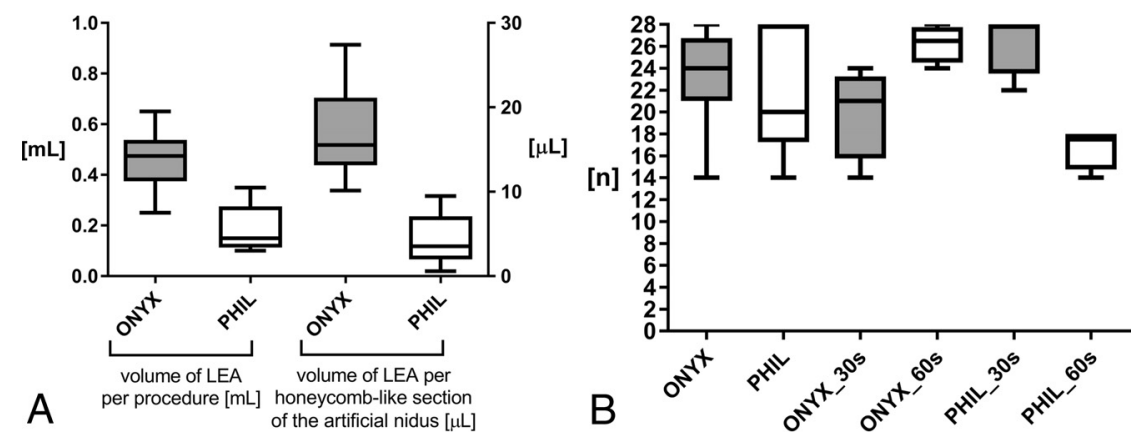

FIG 5. A, Volume of the LEA per procedure (left) and volume of the LEA per honeycomb-like section of the artificial nidus (right). For the same extent of embolization, significantly lower volumes of PHIL were required. $B$, Filled honeycomb-like sections of the artificial nidus. Embolization success was comparable between group Onyx and group PHIL. A pause time of 60 seconds resulted in a considerable, however not statistically significantly, higher embolization success for Onyx. A pause time of 30 seconds resulted in a significantly higher embolization success for PHIL. Onyx indicates Onyx 18; PHIL indicates PHIL 25.

based on a biocompatible copolymer instead of EVOH. For radiopacity, iodine is covalently bound to the copolymer. Three studies reported their preliminary experience with PHIL and demonstrated the effectiveness and safety of PHIL for AVM and AVF embolization, albeit for a limited number of cases. ${ }^{10-12}$ The potential advantages of PHIL over Onyx discussed in the literature are its ease of use, faster plug formation, more consistent visibility, fewer artifacts in postinterventional imaging, lower required volumes of LEA, a constant degree of embolization effect, and no intraoperative hazards. ${ }^{10-12}$

Two studies with an in vitro AVM model were published recently, and in both studies $n$-BCA was the focus of investigation. ${ }^{13,14}$ In contrast to our AVM model, the model used in these studies consisted of commercially available 1-mL syringes filled with small plastic balls, and in the study of Ishikawa et al, ${ }^{13}$ swine blood instead of electrolyte solution was used. Instead of this 1D artificial nidus, in our study, a complex, 3D AVM model was used. For better standardization of the embolization procedures, we consciously used saline solution instead of heparinized swine blood. The flow rates of cerebral AVMs range from 50 to 550 $\mathrm{mL} / \mathrm{min} .{ }^{15,16}$ Accordingly and similar to the 2 in vitro studies mentioned above, the flow rate of $120 \mathrm{~mL} / \mathrm{min}$ in our model represents a moderate-flow AVM nidus. ${ }^{13,14}$ The intraluminal pressures proximal and distal to the artificial nidus (70 and $13 \mathrm{~mm}$ $\mathrm{Hg}$ ) were similar to the intravascular pressures in an AVM (49.3 \pm 16.9 and $17.1 \pm 6.1 \mathrm{~mm} \mathrm{Hg}){ }^{17}$

We could demonstrate that compared with Onyx, lower volumes of PHIL are required for the same extent of embolization. In quantitative terms (calculated by using the medians), $0.23 \mathrm{~mL}$ of PHIL had the same embolization effect as $1.00 \mathrm{~mL}$ of Onyx. This aspect has to be considered when using PHIL in clinical practice.

As initially indicated, the aim of AVM embolization is complete filling of the nidus. Unwanted reflux into the feeding arteries should be minimized because it can cause embolization of nontarget arteries or close the access way before complete filling. ${ }^{8}$ For Onyx and also according to the preliminary experiences for PHIL, a certain degree of reflux is intended because it causes plug formation around the catheter tip, which enables and improves antegrade movement of the LEA and deep penetration of the nidus while simultaneously reducing the risk of reflux after successful plug formation. ${ }^{10-12}$ Regarding the frequency or extent of reflux, no significant differences between Onyx and PHIL were observed. The required time for plug formation was short for both LEAs in our experimental setup.

Premature embolization of the draining veins should be avoided because an increase of intranidal pressure can occur, resulting in intra- or postinterventional hemorrhage. ${ }^{2,3,9}$ PHIL is thought to have a column effect, decreasing forward flow into the venous side of an AVM, diminishing venous obliteration, which may reduce the rate of hemorrhage due to venous outflow obstruction. ${ }^{10}$ However, in our study, the frequency and extent of forward flow into the draining veins of the AVM model was comparable for Onyx and PHIL.

The significantly higher number of filled sections of the artificial nidus at the time of the first reflux or draining vein embolization for group Onyx can be interpreted as a sign of higher intranidal forward flow compared with PHIL. However, the primary end point — final filling of the artificial nidus — did not show significant differences.

Although the embolization success was not different between Onyx and PHIL, the pause time between 2 injections had considerable influence on the extent of filling of the artificial AVM nidus. For Onyx, a pause time of 60 seconds was advantageous; however, without statistical significance; and for PHIL, a pause time of 30 seconds was significantly advantageous. This finding is in accordance with the precipitation times provided by the manufacturers of Onyx and PHIL, with 5 and 3 minutes, respectively. For optimal embolization control, the precipitation time of a LEA should be short enough to avoid distal off-target embolization and long enough to avoid premature embolization of the proximal AVM, resulting in subtotal filling of the AVM., ${ }^{2,3,9}$ In this regard, for effective embolization, the pause time of 30 seconds seems to be appropriate for the specific precipitation time of PHIL. The shorter waiting time has to be considered in the clinical use of the novel LEA PHIL. ${ }^{18}$

There were some limitations to our study. First, the number of trials was small. Second, transferability of an in vitro model to clinical practice is limited. Third, there might be more or other optimal pause times besides the ones used in this study. Fourth, there was constant and not pulsatile flow in the circuit model.

\section{CONCLUSIONS}

Onyx and PHIL showed comparable embolization success in an in vitro AVM model. Pause time between injections had considerable influence on the embolization success. Shorter pause times (30 seconds) resulted in a significantly higher embolization success for PHIL. Compared with Onyx, lower volumes of PHIL were required for the same extent of embolization. 
Disclosures: Dominik F. Vollherbst—OTHER: This study was technically supported by MicroVention and Medtronic. Christian Ulfert-UNRELATED: Travel/Accommodations/Meeting Expenses Unrelated to Activities Listed: MicroVention; OTHER: The study was technically supported by Medtronic and MicroVention. Johannes PfaffUNRELATED: Payment for Lectures Including Service on Speakers Bureaus: Siemens; Travel/Accommodations/Meeting Expenses Unrelated to Activities Listed: Stryker. Martin Bendszus_UNRELATED: Board Membership: Data and Safety Monitoring Board for Vascular Dynamics; Consultancy: Codman Neurovascular, Roche, Guerbet, Boehringer Ingelheim; Grants/Grants Pending: Deutsche Forschungsgemeinschaft, Hopp Foundation, Novartis, Siemens, Guerbet, Stryker, Covidien*; Payment for Lectures Including Service on Speakers Bureaus: Novartis, Roche, Guerbet, Teva Pharmaceutical Industries, Bayer AG, Codman Neurovascular. Markus A. MöhlenbruchRELATED: Provision of Writing Assistance, Medicines, Equipment, or Administrative Support: This study was supported by MicroVention and Medtronic with embolic materials and microcatheters; UNRELATED: Payment for Lectures Including Service on Speakers Bureaus: Codman Neurovascular, MicroVention, Medtronic, phenox. *Money paid to the institution.

\section{REFERENCES}

1. Friedlander RM. Clinical practice. Arteriovenous malformations of the brain. N Engl J Med 2007;356:2704-12 CrossRef Medline

2. Pierot L, Cognard C, Herbreteau D, et al. Endovascular treatment of brain arteriovenous malformations using a liquid embolic agent: results of a prospective, multicentre study (BRAVO). Eur Radiol 2013;23:2838-45 CrossRef Medline

3. van Rooij WJ, Sluzewski M, Beute GN. Brain AVM embolization with Onyx. AJNR Am J Neuroradiol 2007;28:172-77; discussion 178 Medline

4. Gross BA, Du R. Diagnosis and treatment of vascular malformations of the brain. Curr Treat Options Neurol 2014;16:279 CrossRef Medline

5. Taki W, Yonekawa $Y$, Iwata $\mathrm{H}$, et al. A new liquid material for embolization of arteriovenous malformations. AJNR Am J Neuroradiol 1990;11:163-68 Medline

6. Bruno CA Jr, Meyers PM. Endovascular management of arteriovenous malformations of the brain. Interv Neurol 2013;1:109-23 CrossRef Medline

7. Hu YC, Newman CB, Dashti SR, et al. Cranial dural arteriovenous fistula: transarterial Onyx embolization experience and technical nuances. J Neurointerv Surg 2011;3:5-13 CrossRef Medline

8. Elsenousi A, Aletich VA, Alaraj A. Neurological outcomes and cure rates of embolization of brain arteriovenous malformations with n-butyl cyanoacrylate or Onyx: a meta-analysis. J Neurointerv Surg 2016;8:265-72 CrossRef Medline

9. Ayad M, Eskioglu E, Mericle RA. Onyx: a unique neuroembolic agent. Expert Rev Med Devices 2006;3:705-15 CrossRef Medline

10. Kocer N, Hanımoğlu H, Batur Ş, et al. Preliminary experience with precipitating hydrophobic injectable liquid in brain arteriovenous malformations. Diagn Interv Radiol 2016;22:184-89 CrossRef Medline

11. Samaniego EA, Kalousek V, Abdo G, et al. Preliminary experience with Precipitating Hydrophobic Injectable Liquid (PHIL) in treating cerebral AVMs. J Neurointerv Surg 2016 Jan 27. [Epub ahead of print] CrossRef Medline

12. Leyon JJ, Chavda S, Thomas A, et al. Preliminary experience with the liquid embolic material agent PHIL (precipitating hydrophobic injectable liquid) in treating cranial and spinal dural arteriovenous fistulas: technical note. J Neurointerv Surg 2016;8:596-602 CrossRef Medline

13. Ishikawa M, Horikawa M, Yamagami T, et al. Embolization of arteriovenous malformations: effect of flow control and composition of n-butyl-2 cyanoacrylate and iodized oil mixtures with and without ethanol in an in vitro model. Radiology 2016;279:910-16 CrossRef Medline

14. Inagawa $\mathrm{S}$, Isoda $\mathrm{H}$, Kougo $\mathrm{H}$, et al. In-vitro simulation of NBCA embolization for arteriovenous malformation. Interv Neuroradiol 2003;9:351-58 CrossRef Medline

15. Chang W, Loecher MW, Wu Y, et al. Hemodynamic changes in patients with arteriovenous malformations assessed using high-resolution 3D radial phase-contrast MR angiography. AJNR Am J Neuroradiol 2012;33:1565-72 CrossRef Medline

16. Nornes H, Grip A. Hemodynamic aspects of cerebral arteriovenous malformations. J Neurosurg 1980;53:456-64 CrossRef Medline

17. Rossitti S. Pathophysiology of increased cerebrospinal fluid pressure associated to brain arteriovenous malformations: the hydraulic hypothesis. Surg Neurol Int 2013;4:42 CrossRef Medline

18. Frontera JA, Moatti J, de los Reyes KM, et al. Safety and cost of stentassisted coiling of unruptured intracranial aneurysms compared with coiling or clipping. J Neurointerv Surg 2014;6:65-71 CrossRef Medline 